\title{
Fatores associados a acidentes de trânsito entre condutores de veículos: achados de um estudo de base populacional
}

\author{
Factors associated with traffic accidents among drivers: findings \\ from a population-based study
}

Polianna Alves Andrade Rios (https://orcid.org/0000-0002-6318-2230) ${ }^{1}$

Eduardo Luiz Andrade Mota (https://orcid.org/0000-0001-7819-0084) ${ }^{2}$

Luciano Nery Ferreira (https://orcid.org/0000-0002-9410-2467) ${ }^{3}$

Jefferson Paixão Cardoso (https://orcid.org/0000-0003-0128-5792) ${ }^{1}$

Vivian Mara Ribeiro (https://orcid.org/0000-0002-8860-4428) ${ }^{1}$

Bruna Silva de Souza (https://orcid.org/0000-0003-1608-8046) ${ }^{4}$
${ }^{1}$ Departamento de Saúde II, Universidade Estadual do Sudoeste da Bahia. Av. José Moreira Sobrinho $\mathrm{s} / \mathrm{n}$, Jequiezinho. 45205490 Jequié BA Brasil. polianauesb@yahoo.com.br ${ }^{2}$ Instituto de Saúde Coletiva, Universidade Federal da

Bahia. Salvador BA Brasil ${ }^{3}$ Departamento de Saúde I, Universidade Estadual do Sudoeste da Bahia. Jequié BA Brasil.

${ }^{4}$ Curso de Fisioterapia, Universidade Estadual do Sudoeste da Bahia. Jequié BA Brasil.

\begin{abstract}
This study aimed to identify associated factors with drivers' involvement in traffic accidents (TA). Thus, in 2013, a household survey was conducted with 1,406 drivers in Jequie, Bahia, Brazil. A hierarchical conceptual model was established and consisted of four blocks of exposure factors, considering the proximal-distal relationships between them and the outcome. Multilevel logistic regression was applied to estimate the Odds Ratio (OR) and 95\% Confidence Intervals $(95 \% C I)$. Higher TA probability was observed among drivers aged 15-29 years $(\mathrm{OR}=3.15$; 95\%CI 1.24-8.02), with black or brown skin color $(\mathrm{OR}=1.56 ; 95 \% \mathrm{CI}$ 1.03-2.35), motorcyclists $(O R=1.73$; 95\%CI 1.15-2.60), with a history of traffic tickets (OR=1.75; 95\%CI 1.04-2.94), who reported drinking and driving $(\mathrm{OR}=1.68$; 95\%CI $1.12-2.53)$ and used cell phone while driving $(\mathrm{OR}=1.63$; 95\%CI 1.09-2.43). Proximal factors changed the exposure association measures concerning higher levels of determination of the hierarchical model, mainly regarding the gender variable. The results emphasize the behavioral factors and reaffirm the TAs' preventable potential due to the occurrence of avoidable conditions associated with the outcome.
\end{abstract}

Key words Traffic Accidents, Health Surveys, Epidemiologic factors, Automobile driving
Resumo O estudo teve por objetivo identificar fatores associados ao envolvimento em acidentes de trânsito (AT) entre condutores de veículos. Para isso, realizou-se inquérito domiciliar na cidade de Jequié, Bahia, em 2013, com 1.406 condutores. Elaborou-se um modelo conceitual hierarquizado composto por quatro blocos de fatores de exposição, considerando as relações proximais-distais entre estes e o desfecho. Foi empregado modelo de regressão logística multinivel para as estimativas de Razão de Chances (RC) e Intervalos de Confiança a 95\% (IC95\%). Observou-se maior chance de AT entre condutores de 15 a 29 anos $(R C=3,15 ; \quad I C 95 \%$ 1,24-8,02); de cor da pele preta ou parda ( $R C=1,56$; IC95\% 1,03-2,35); motociclistas ( $R C=1,73$; IC95\% 1,15-2,60); com antecedentes de multa no trânsito $(R C=1,75$; IC95\% 1,04-2,94); que referiram beber e dirigir (RC=1,68; IC95\% 1,12-2,53) e usar telefone celular durante a condução (RC=1,63; IC95\% 1,09-2,43). Os fatores proximais modificaram as medidas de associação das exposições dos niveis superiores do modelo hierarquizado, principalmente da variável sexo. Os resultados enfatizam os fatores comportamentais e ratificam o potencial de prevenção dos AT, em virtude da ocorrência de condições evitáveis associadas ao desfecho.

Palavras-chave Acidentes de Trânsito, Inquéritos epidemiológicos, Fatores epidemiológicos, Condução de veículo 


\section{Introdução}

O sinal distintivo de que os acidentes de trânsito (AT) se estabeleceram como grave problema de saúde pública mundial é a sua crescente participação no conjunto de causas de morbimortalidade, ceifando a vida de mais de um milhão de pessoas e produzindo até 50 milhões de incapacitados no mundo a cada ano ${ }^{1}$. Além do desmedido custo humano, esses eventos também afetam negativamente o desenvolvimento de sociedades, por meio dos altos custos em saúde, em assistência previdenciária, danos materiais e perda produtiva ${ }^{2,3}$.

Esse ônus social e econômico é pago, em grande parte, pelos países em desenvolvimento, que respondem por mais de $90,0 \%$ das fatalidades do trânsito ${ }^{1}$. Embora sejam eventos preveníveis, a tendência para a morbimortalidade relacionada ao tráfego viário nesses locais é de crescimento, o que pode colocar os AT como a quinta causa mais frequente de óbito até 2030 no mundo ${ }^{1-4}$. Tal panorama fez com que a segurança viária ganhasse espaço na pauta de Organismos Internacionais, principalmente no início do século vinte e um. Por isso, em 2010, as Nações Unidas anunciaram a Década de Ação para Segurança Viária (20112020) com o intuito de estabilizar e reduzir as mortes causadas pelo trânsito a partir de ações conduzidas em nível nacional, regional e global ${ }^{5}$.

O Brasil participa dessa iniciativa internacional, denominada no país como Projeto Vida no Trânsito (PVT) ${ }^{6}$. Mesmo tendo assumido o compromisso com a segurança viária, os AT ainda produzem vítimas fatais e não fatais em magnitude assustadora no país, colocando em dúvida a sua capacidade de alcançar as metas estabelecidas para enfrentar este problema ${ }^{7}$. Segundo o Ministério da Saúde, os acidentes de trânsito causaram a morte de 38.651 pessoas $^{8}$ em 2015 e geraram, aproximadamente, 158 mil internações em hospitais do Sistema Único de Saúde 9 . Embora esses números já mostrem uma situação preocupante, sabe-se que parte da magnitude dos AT ainda permanece pouco conhecida. Entretanto, outras fontes de informação têm contribuído para o dimensionamento do problema dos acidentes, como o Projeto VIVA (Vigilância de Violências e Acidentes), que registra os atendimentos em serviços de urgência e emergência. Em todas essas fontes, observa-se crescimento do número de vítimas de acidentes entre ocupantes de veículos, sobretudo entre condutores de motocicletas ${ }^{10,11}$.

Alguns inquéritos nacionais, conduzidos em 2008 (Pesquisa Nacional por Amostra de Domi- cílio - PNAD) e 2013 (Pesquisa Nacional de Saúde - PNS), abordaram o tema dos AT e estimaram proporções de envolvimento nesses eventos na ordem de $2,5 \%{ }^{12}$ e $3,1 \%{ }^{13}$, respectivamente, para a população brasileira. Entretanto, no intervalo temporal entre essas duas pesquisas, observou-se mudança do perfil dos acidentes quanto à categoria de vítima, com redução do percentual de ocupantes de carro e aumento para os motociclistas, grupo que representou mais que $60,0 \%$ de todos os que sofreram lesão por AT nas regiões Norte e Nordeste em $2013^{14}$.

Ainda que o país apresente variadas fontes de informação, reconhece-se a escassez de dados sobre acidentes de trânsito a partir de fontes primárias, de base populacional, que possam identificar vítimas não captadas pelos sistemas de informação usuais, e referentes a municípios que não se constituem em grandes centros urbanos, onde se verifica progressiva ampliação da participação das causas externas na morbimortalidade local ${ }^{15,16}$. Nesse sentido, ganha relevância a realização de inquéritos populacionais com o intuito de contribuir para o conhecimento da extensão do problema dos AT e dos fatores determinantes.

A esse respeito, a literatura científica evidencia que os acidentes de trânsito apresentam determinação complexa e multifacetada. O referencial ecológico proposto por Haddon tem sido o mais utilizado nas pesquisas da área da saúde sobre o tema e estabelece causas relacionadas à pessoa, ao veículo e aos ambientes físico (viário) e sociocultural, que interagem para a ocorrência dos $\mathrm{AT}^{17}$. Dentre essas causas, o fator humano é considerado como elemento de maior participação na geração dos acidentes ${ }^{18}$. No entanto, convém explicitar que, embora tal fator constitua manifestação individual de condutas no trânsito, ele é determinado por uma rede complexa que inclui desde características psicológicas ${ }^{18} \mathrm{e}$ questões de gênero, a determinantes culturais e socioeconômicos ${ }^{17}$. Nesse sentido, o PVT elegeu dois fatores de risco, de ordem comportamental, como prioritários para intervenções no Brasil: o comportamento de beber e dirigir; e velocidade excessiva ou inadequada ${ }^{6}$.

Assim, considerando o problema dos acidentes de transporte terrestre no país e a importância de produzir informações sobre determinantes desses eventos a partir de pesquisas de base populacional, realizou-se este estudo com o objetivo de identificar fatores associados ao envolvimento em AT entre condutores de veículos no município de Jequié, Bahia. 


\section{Métodos}

Estudo transversal, de base populacional, que constituiu a etapa de linha de base de uma pesquisa longitudinal sobre acidentes de trânsito, seus determinantes e repercussões na vida das pessoas envolvidas, realizada no município de Jequié, Bahia, entre 2013 e 2015. Os dados deste artigo referem-se ao ano 2013, quando a coorte foi constituída por meio de inquérito domiciliar.

O município de Jequié faz parte da região Sudoeste da Bahia e localiza-se a $365 \mathrm{~km}$ da capital do estado ${ }^{19}$, estando fora do eixo metropolitano. Em 2013, sua população foi estimada em 161.391 habitantes ${ }^{20}$ e apresentava 30,8 veículos para cada 100 residentes, com maior relação de motocicleta do que automóvel por habitante (15,5 motos e 10,4 carros por 100 habitantes, respectivamente) ${ }^{20,21}$.

Os participantes do estudo foram condutores de veículos motorizados terrestres (automóveis, caminhonetes, motocicletas, motonetas, ciclomotores, van, ônibus e caminhões), que residiam em domicílio particular da zona urbana do município. O corte mínimo da idade para inclusão na pesquisa foi de 14 anos devido à possibilidade de encontrar adolescentes conduzindo veículos, em especial os ciclomotores. Foram excluídos os moradores de domicílios temporários, tendo em vista a necessidade da fase de acompanhamento da pesquisa longitudinal na qual este estudo está inserido.

A amostra foi calculada no programa EPI-Info (Versão 6.0), com base nos seguintes parâmetros: proporção de envolvimento em $\mathrm{AT}=9,0 \%$ (proporção determinada a partir dos achados de um Inquérito de Saúde e Nutrição, no qual 7,8\% dos adultos referiram envolvimento em AT nos últimos 12 meses, como qualquer usuário da via pública $^{22}$. Como a presente pesquisa abordou a população de condutores de veículos, considerou-se pertinente a projeção da frequência para $9,0 \%) ; \alpha=5,0 \%$; precisão $=2,0 \%$; e efeito de desenho $=2$; o que resultou em um tamanho amostral de 1.572 condutores.

Para a seleção dos participantes foi utilizada amostragem por conglomerado em estágio único, com sorteio de 35 Setores Censitários (SC), dos 169 SC urbanos que o município apresentava ${ }^{23}$. Esse quantitativo foi estabelecido levando em conta alguns critérios atribuídos pelos pesquisadores - após realização de estudo piloto em um SC, verificou-se que a fração de acesso à população de pesquisa representou, aproximadamente, um terço de todos os domićlios do setor. Dessa maneira, considerando tal fração no número médio de domicílios por SC (241 domicílios/SC23); a densidade média de dois adultos por domicílio, sendo um deles um provável condutor; e possibilidade de encontrar residências sem condutores, devido à condição socioeconômica de algumas regiões do município, levantou-se que, em média, 60 domicílios por SC poderiam ser incluídos no estudo. Assim, seriam necessários 26 SC para a amostra. Entretanto, alguns setores sorteados possuíam número de domicílios menor que a média municipal, o que fez com o quantitativo fosse ampliado para 35 setores.

A coleta de dados do inquérito ocorreu entre julho e outubro de 2013. Os entrevistadores percorreram todas as quadras dos SC selecionados, com mapas disponibilizados via internet pelo IBGE, e abordaram todos os domicílios para verificar a existência de condutores. Para as residências onde não foi possível entrevistar todos os elegíveis, ausentes ou impossibilitados de participar na primeira abordagem, agendaram-se visitas em horário conveniente ao participante. Estabeleceu-se o número máximo de três tentativas de agendamento, ou retorno ao domicílio fechado em horários distintos, para, em caso de insucesso, considerar o condutor/domicílio como não resposta. A média de condutores entrevistados por domicílio participante foi de 1,2 para os 35 SC, variando de 1,0 a 1,4 condutor/domicílio.

Os dados foram produzidos por meio de entrevistas com formulário estruturado e consulta na base de dados do Censo 2010 do IBGE, para obter informação sobre a renda dos setores censitários.

A variável dependente do estudo foi o envolvimento autorreferido em acidente de trânsito nos 12 meses anteriores à entrevista, estando na condição de condutor no momento do AT (sim; não). A definição de AT adotada na pesquisa foi: "todo acidente com veículo ocorrido na via pública, o que inclui qualquer atropelamento, colisão entre veículos, acidentes com bicicleta, moto e quedas dentro de ônibus (ou para fora dele), quedas de caminhão e motos que ocorrem em ruas ou estradas, podendo ou não causar ferimentos nas pessoas" (definição adaptada dos conceitos da Classificação Internacional de Doenças, 10ª Revisão ${ }^{24} \mathrm{e}$ do estudo de Magalhães et al. ${ }^{25}$ ).

As variáveis independentes foram organizadas em blocos para análise multivariada, a saber:

- Bloco 1 - Variável de vizinhança: renda média do SC (representada pelo rendimento mensal das pessoas com 10 anos de idade e mais, com e sem rendimento, categorizada em: menor que 
$\mathrm{R} \$ 500,00$; de $\mathrm{R} \$ 500,00$ a $\mathrm{R} \$ 724,00$; e maior que $\mathrm{R} \$ 724,00)$.

- Bloco 2 - Sociodemográficas: sexo (masculino; feminino), faixa etária ( 15 a 29 anos; 30 a 44 anos; 45 a 59 anos; 60 anos e mais), cor da pele (preta ou parda; branca), convivência marital (sim; não), escolaridade (superior completo; $2^{\circ}$ grau completo; $1^{\circ}$ grau completo).

- Bloco 3 - Experiências no trânsito: possui Carteira Nacional de Habilitação (CNH) (sim; não), antecedente de multa no trânsito nos últimos 12 meses (sim; não), opinião favorável à "nova" Lei Seca (Lei no 12.760/2012) (sim; não), e tipo de condutor (motociclista; motorista). Esta última variável derivou do questionamento sobre o tipo de veículo que o participante referiu conduzir mais frequentemente e foi categorizada em: "motorista", para os que referiram automóvel ou outros veículos de quatro ou mais rodas, e "motociclista", para os que referiram motocicleta, motoneta ou ciclomotor.

- Bloco 4 - Comportamentos no trânsito: beber e dirigir (ingestão de qualquer quantidade de bebida alcoólica) (sim; não), usar telefone celular enquanto dirige (sim; não), referir gostar de correr ao dirigir (sim; não), e adotar velocidade insegura em via urbana (sim: $>50 \mathrm{~km} / \mathrm{h}$; não: $\leq 50$ $\mathrm{km} / \mathrm{h}$ ), variável categorizada a partir do questionamento sobre a velocidade máxima que costuma dirigir.

O critério de corte para definição de velocidade insegura nesta pesquisa foi baseado em relatórios da Organização Mundial da Saúde (OMS), que considera $50 \mathrm{~km} / \mathrm{h}$ como a melhor prática para os limites em área urbana, pois tanto reduzem as chances de AT quanto minimizam lesões e mortes ${ }^{1,4}$.

O software Stata ${ }^{\oplus}$, versão 12.0 , foi utilizado para análise dos dados. Foram estimadas frequências das variáveis para descrição das características dos participantes e, para comparação entre as proporções de AT, foi empregado o teste Qui-Quadrado Rao-Scott ( $\mathrm{p} \leq 0,05)$; versão que se adequa a dados com estrutura de dependência devido ao desenho amostral utilizado.

A análise de fatores associados foi baseada em um modelo conceitual hierarquizado (Figura 1), elaborado de acordo às relações proximais-distais das exposições e do desfecho. A estratégia hierarquizada de análise apresenta algumas vantagens em comparação com a análise multivariada tradicional, pois é adequada para situações nas quais se tem um grande número de variáveis, além de considerar relações de mediação que podem existir na determinação dos fenômenos em estudo ${ }^{26}$.
Foi empregado o modelo de Regressão Logística Multinível para as estimativas de Razão de Chances (RC) e Intervalos de Confiança a 95\% (IC95\%), com uso da sintaxe $x$ tlogit, do Stata ${ }^{\circ}$. A escolha do modelo de regressão multinível também leva em consideração a estrutura de dependência dos dados, portanto, as estimativas levaram em conta o efeito do desenho do estudo. Para a seleção das variáveis na modelagem, estabeleceram-se valores de $\mathrm{p} \leq 0,20$ na etapa bivariada e $\mathrm{p} \leq 0,10$ na multivariada-intrablocos. $\mathrm{Na}$ etapa hierarquizada, considerou-se $\mathrm{p} \leq 0,05$ para significância estatística. $O$ teste da razão de máxima verossimilhança foi utilizado para avaliar a permanência das variáveis no modelo.

Todos os preceitos éticos foram seguidos no estudo. O projeto foi aprovado pelo Comitê de Ética em Pesquisa do Instituto de Saúde Coletiva, da Universidade Federal da Bahia.

\section{Resultados}

Da amostra de 1.572 condutores, 1.407 foram entrevistados e 165 pessoas não foram encontradas no domicílio em todas as tentativas estipuladas para realização da entrevista. Um participante foi excluído da análise devido ao número de dados faltantes do formulário de entrevista. Assim, o percentual de perda amostral situou-se em $10,6 \%$, e os resultados do artigo referem-se a 1.406 pessoas. $\mathrm{O}$ envolvimento em acidentes de trânsito nos últimos 12 meses, na condição de condutor de veículo, foi referido por 10,4\% (147) dos participantes.

Na Tabela 1, observa-se que as frequências de envolvimento em AT variaram de acordo a categorias dos fatores de exposição, com resultados estatisticamente significantes para maior proporção de AT em pessoas jovens, de cor da pele preta ou parda, sem convivência marital, que dirigem motocicleta, não sendo habilitados, com antecedentes de multa, que não concordavam com a "nova" Lei Seca e que relataram comportamentos inseguros e ilegais no trânsito.

No modelo de regressão bivariado verificou-se que a renda média do SC e a escolaridade não estiveram associadas ao desfecho. As demais variáveis seguiram para o modelo multivariado (intrablocos). Embora a renda do SC não tenha apresentado valor de $\mathrm{p}<0,20$, ela foi mantida nas outras etapas da análise por se tratar de uma variável contextual. Observa-se que o desfecho se manteve associado, no Bloco 2, com sexo, faixa etária, cor da pele e convivência marital. 
Bloco 3

Experiências relacionadas ao trânsito

Tipo de condutor Possui Carteira

Nacional de Habilitação

Multa Opinião favorável à Lei Seca

Comportamentos de risco no trânsito como
condutor
Bloco $4 \quad$ Referir gostar de correr
adirigir dirigir veículo
Adotar velocidade insegura em via
urbana
Usar celular ao dirigir

Desfecho

Envolvimento em acidentes de trânsito na condição de condutor

Figura 1. Modelo conceitual hierarquizado para análise de fatores associados ao envolvimento em acidentes de trânsito entre condutores de veículos.

No Bloco 3, apresentou associação com tipo de condutor, antecedente de multa de trânsito, não concordar com a "nova” Lei Seca. Já no Bloco 4, não se associou somente a "adotar velocidade insegura em via urbana” (Tabela 2).

$\mathrm{Na}$ Tabela 3, encontram-se os resultados da análise hierarquizada a partir dos modelos $\mathrm{A}$ (Blocos 1 e 2), B (Blocos 1, 2 e 3 ) e C (Blocos 1, 2, 3 e 4). No modelo A, observou-se o efeito direto da associação entre envolvimento em AT e sexo, faixa etária e convivência marital, ajustado pela renda do SC. A chance de envolvimento em AT entre homens foi 52,0\% maior do que para mulheres, ajustado pelas demais variáveis. Quanto à faixa etária, observaram-se valores maiores de razão de chances entre pessoas de 15 a 29 anos e entre 30 a 44 anos.

No modelo B, após introdução do Bloco 3, pôde-se observar o efeito direto das variáveis antecedente de multa no trânsito e tipo de condutor, ajustada pelas variáveis dos Blocos 1 e 2 . A inclusão do Bloco 3 promoveu redução das ra- zões de chance de envolvimento em AT para as variáveis faixa etária e sexo, com destaque para esta última, que deixou de estar associada no Modelo B ( $\mathrm{RC}=1,40$ e IC95\% 0,94-2,08) (Tabela 3).

Com a introdução do Bloco 4, o Modelo C foi ajustado e constituiu o modelo final de fatores associados. Assim, estimou-se o efeito direto dos comportamentos de beber e dirigir $(\mathrm{RC}=1,68$; IC95\% 1,12-2,53) e do uso de celular durante a condução ( $\mathrm{RC}=1,63$; IC95\% 1,09-2,43) sobre o envolvimento em acidentes, ajustados pelas demais variáveis. Neste modelo, observou-se aumento nas razões de chance de algumas variáveis (tipo de condutor e cor da pele) e redução para outras (antecedentes de multa, faixa etária e sexo). Desse modo, estiveram associados ao envolvimento em AT os seguintes fatores: faixa etária, com razão de chance de 3,15 para condutores de 15 a 29 anos (IC95\% 1,24-8,02); cor da pele, com chance de envolvimento $56,0 \%$ maior entre os que se declararam pardos ou pretos (IC95\% 1,03-2,35); tipo de condutor, tendo o motociclista chance $73,0 \%$ 
Tabela 1. Características da população do estudo e frequências absolutas e relativas de acidentes de trânsito (AT) entre condutores de veículos, segundo categorias das variáveis sociodemográficas e relacionadas ao trânsito. Jequié, Bahia, $2013(\mathrm{n}=1.406)$.

\begin{tabular}{|c|c|c|c|c|c|}
\hline \multirow[t]{2}{*}{ Variáveis } & \multicolumn{2}{|c|}{$\begin{array}{l}\text { População do } \\
\text { estudo }\end{array}$} & \multicolumn{2}{|c|}{$\begin{array}{c}\text { Envolvimento em } \\
\text { AT }\end{array}$} & \multirow[t]{2}{*}{ valor de $\mathrm{p}^{\mathrm{a}}$} \\
\hline & $\mathbf{N}$ & $\%$ & $\mathbf{N}$ & $\%$ & \\
\hline Sexo & & & & & 0,230 \\
\hline Masculino & 934 & 66,4 & 106 & 11,3 & \\
\hline Feminino & 472 & 33,6 & 41 & 8,7 & \\
\hline Faixa etária (em anos) & & & & & 0,000 \\
\hline 15 a 29 & 367 & 26,1 & 62 & 16,9 & \\
\hline 30 a 44 & 517 & 36,8 & 57 & 11,0 & \\
\hline 45 a 59 & 336 & 23,9 & 22 & 6,5 & \\
\hline 60 e mais & 186 & 13,2 & 6 & 3,2 & \\
\hline Cor da pele & & & & & 0,031 \\
\hline Preta ou parda & 949 & 67,5 & 111 & 11,7 & \\
\hline Branca & 457 & 32,5 & 36 & 7,9 & \\
\hline Convivência marital & & & & & 0,000 \\
\hline Não & 550 & 39,1 & 79 & 14,4 & \\
\hline $\operatorname{Sim}$ & 856 & 60,9 & 68 & 7,9 & \\
\hline Escolaridade & & & & & 0,237 \\
\hline Superior completo & 298 & 21,2 & 37 & 12,4 & \\
\hline $2^{\circ}$ grau completo & 720 & 51,2 & 70 & 9,7 & \\
\hline $1^{\circ}$ grau completo & 388 & 27,6 & 40 & 10,3 & \\
\hline Renda média do Setor Censitário & & & & & 0,985 \\
\hline Menos de 500,00 reais & 413 & 29,4 & 44 & 10,6 & \\
\hline 500,00 a 724,00 reais & 454 & 32,3 & 48 & 10,6 & \\
\hline Mais de 724,00 reais & 539 & 38,3 & 55 & 10,2 & \\
\hline Tipo de condutor & & & & & 0,000 \\
\hline Motociclista & 549 & 39,1 & 81 & 14,8 & \\
\hline Motorista & 857 & 60,9 & 66 & 7,7 & \\
\hline Carteira Nacional de Habilitação & & & & & 0,002 \\
\hline Não & 243 & 17,3 & 36 & 14,8 & \\
\hline Sim & 1.163 & 82,7 & 111 & 9,5 & \\
\hline Antecedentes de multa no trânsito & & & & & 0,014 \\
\hline Sim & 129 & 9,2 & 23 & 17,8 & \\
\hline Não & 1.277 & 90,8 & 124 & 9,7 & \\
\hline Opinião favorável à “nova” Lei Seca & & & & & 0,113 \\
\hline Não & 79 & 5,6 & 14 & 17,7 & \\
\hline Sim & 1.327 & 94,4 & 133 & 10,0 & \\
\hline Beber e dirigir & & & & & 0,003 \\
\hline Sim & 286 & 20,3 & 50 & 17,5 & \\
\hline Não & 1.120 & 79,7 & 97 & 8,7 & \\
\hline Adota velocidade insegura em via urbana & & & & & 0,025 \\
\hline $\operatorname{Sim}(>50 \mathrm{~km} / \mathrm{h})$ & 631 & 44,9 & 80 & 12,7 & \\
\hline Não $(\leq 50$ km/h) & 775 & 55,1 & 67 & 8,7 & \\
\hline Refere gostar de correr ao dirigir & & & & & 0,000 \\
\hline Sim & 264 & 18,8 & 46 & 17,4 & \\
\hline Não & 1.142 & 81,2 & 101 & 8,8 & \\
\hline Uso de celular enquanto dirige & & & & & 0,000 \\
\hline Sim & 382 & 27,2 & 60 & 15,7 & \\
\hline Não & 1.024 & 72,8 & 87 & 8,5 & \\
\hline
\end{tabular}

${ }^{\mathrm{a}}$ Teste Qui-Quadrado com correção Rao \& Scott. ${ }^{\mathrm{b}}$ Cor da pele autodeclarada; branca: inclui condutores que se declararam brancos e amarelos. 
Tabela 2. Valores de Razão de Chances (RC) das análises de regressão bivariada e multivariada intrablocos para fatores associados a acidentes de trânsito (AT) entre condutores de veículos. Jequié, Bahia, 2013 ( $\mathrm{n}=1.406)$.

\begin{tabular}{|c|c|c|c|c|}
\hline \multirow{2}{*}{ Variáveis } & \multicolumn{2}{|c|}{ Bivariada } & \multicolumn{2}{|c|}{ Multivariada intrablocos } \\
\hline & RC & valor de $\mathrm{p}^{\mathrm{b}}$ & RC & valor de $\mathbf{p}^{\mathrm{c}}$ \\
\hline \multicolumn{5}{|l|}{ Nível Contextual } \\
\hline \multicolumn{5}{|l|}{ Bloco 1: Vizinhança } \\
\hline \multicolumn{5}{|c|}{ Renda média do Setor Censitário ${ }^{\mathrm{d}}$} \\
\hline Menos de 500,00 reais & 1,06 & 0,808 & 1,06 & 0,808 \\
\hline 500,00 a 724,00 reais & 1,05 & 0,837 & 1,05 & 0,837 \\
\hline \multicolumn{5}{|l|}{$\begin{array}{l}\text { Nível Individual } \\
\text { Bloco 2: Sociodemográficas }\end{array}$} \\
\hline \multicolumn{5}{|l|}{ Sexo } \\
\hline Masculino & 1,35 & 0,120 & 1,49 & 0,044 \\
\hline \multicolumn{5}{|l|}{ Faixa etária (em anos) } \\
\hline 15 a 29 & 6,22 & 0,000 & 5,42 & 0,000 \\
\hline 30 a 44 & 3,73 & 0,003 & 3,81 & 0,002 \\
\hline 45 a 59 & 2,12 & 0,110 & 2,26 & 0,084 \\
\hline \multicolumn{5}{|l|}{ Cor da pele ${ }^{e}$} \\
\hline Preta ou parda & 1,54 & 0,032 & 1,47 & 0,061 \\
\hline \multicolumn{5}{|l|}{ Convivência marital } \\
\hline Não & 1,97 & 0,000 & 1,50 & 0,038 \\
\hline \multicolumn{5}{|l|}{ Escolaridade } \\
\hline Superior completo & 1,22 & 0,399 & - & - \\
\hline $2^{\circ}$ grau completo & 0,93 & 0,767 & - & - \\
\hline \multicolumn{5}{|c|}{ Bloco 3: Experiências no trânsito } \\
\hline \multicolumn{5}{|c|}{ Tipo de condutor } \\
\hline Motociclista & 2,08 & 0,000 & 2,02 & 0,000 \\
\hline \multicolumn{5}{|c|}{ Carteira Nacional de Habilitação } \\
\hline Não & 1,66 & 0,015 & 1,31 & 0,215 \\
\hline \multicolumn{5}{|l|}{ Antecedentes de multa } \\
\hline Sim & 2,04 & 0,004 & 2,18 & 0,002 \\
\hline \multicolumn{5}{|c|}{ Opinião favorável à “nova” Lei Seca } \\
\hline Não & 1,92 & 0,035 & 1,77 & 0,069 \\
\hline \multicolumn{5}{|c|}{ Bloco 4: Comportamentos no trânsito } \\
\hline \multicolumn{5}{|c|}{ Beber e dirigir } \\
\hline Sim & 2,23 & 0,000 & 1,76 & 0,005 \\
\hline \multicolumn{5}{|c|}{ Adota velocidade insegura em via urbana } \\
\hline $\operatorname{Sim}(>50 \mathrm{~km} / \mathrm{h})$ & 1,53 & 0,015 & 1,25 & 0,211 \\
\hline \multicolumn{5}{|c|}{ Refere gostar de correr ao dirigir } \\
\hline Sim & 2,20 & 0,000 & 1,69 & 0,011 \\
\hline \multicolumn{5}{|l|}{ Uso de celular enquanto dirige } \\
\hline Sim & 2,00 & 0,000 & 1,51 & 0,035 \\
\hline $\begin{array}{l}{ }^{2} \text { Análise de Regressão Logística Mu } \\
\text { análise; }{ }^{\mathrm{c}} \text { Valor de } \mathrm{p}<0,10 \text { para per } \\
\text { Censitário foi mantida nas etapas d } \\
\text { condutores que se declararam bran } \\
\text { Sexo: feminino; Faixa etária: } 60 \text { ano } \\
\text { de condutor: motorista (de automó } \\
\text { sim; Antecedentes de multa: não; } O\end{array}$ & $\begin{array}{l}\text { para p } \\
\text { trada nc } \\
\text { Ima var } \\
\text { as de re } \\
\text { aca; Cor } \\
\text { com ma } \\
\text { Lei Seca }\end{array}$ & $\begin{array}{l}\text { Encia no model } \\
\text { e hierarquizada } \\
\text { ntextual; }{ }^{\text {e Cor }} \\
\text { : Renda média } \\
\text { ia marital: sim; } \\
\text { latro rodas); Po } \\
\text { Seber e dirigir: } 1\end{array}$ & $\begin{array}{l}\text { trada na } \\
\text { variável } r \\
\text { le autode } \\
\text { tor Cens } \\
\text { laridade: } \\
\text { Carteira I } \\
\text { elocidad }\end{array}$ & $\begin{array}{l}\text { nultivariada da } \\
\text { édia do Setor } \\
\text {; branca: inclui } \\
\text { nais de } \mathrm{R} \$ 724,00 \text {; } \\
\text { completo; Tipo } \\
\text { le Habilitação: } \\
\text { na em via urbana: }\end{array}$ \\
\hline
\end{tabular}

maior que os motoristas (IC95\% 1,15-2,60); convivência marital; antecedente de multa no trânsi- to; e os comportamentos de beber e dirigir e usar telefone celular enquanto dirige (Tabela 3). 
Tabela 3. Valores de Razão de Chances (RC) e Intervalos de Confiança a 95\% (IC95\%) da análise hierarquizada ${ }^{\mathrm{a}}$ para fatores associados a acidentes de trânsito (AT) entre condutores de veículos. Jequié, Bahia, 2013 ( $\mathrm{n}=1.406$ ).

\begin{tabular}{|c|c|c|c|}
\hline \multirow{3}{*}{ Variáveis } & \multicolumn{3}{|c|}{ Envolvimento em acidentes de trânsito } \\
\hline & $\begin{array}{c}\text { Modelo A } \\
\text { (Blocos } 1 \text { e 2) }\end{array}$ & $\begin{array}{c}\text { Modelo B } \\
(\text { Blocos 1, } 2 \text { e 3) }\end{array}$ & $\begin{array}{c}\text { Modelo C } \\
(\text { Blocos1, 2, } 3 \text { e 4) }\end{array}$ \\
\hline & RC (IC95\%) & RC (IC95\%) & RC (IC95\%) \\
\hline \multicolumn{4}{|l|}{ Bloco 1: Vizinhança } \\
\hline \multicolumn{4}{|l|}{ Renda média do SC ${ }^{b}$} \\
\hline Menos de 500,00 reais & $0,80(0,50-1,28)$ & $0,73(0,45-1,19)$ & $0,77(0,49-1,29)$ \\
\hline 500,00 a 724,00 reais & $0,88(0,55-1,40)$ & $0,84(0,52-1,35)$ & $0,88(0,55-1,41)$ \\
\hline \multicolumn{4}{|l|}{ Bloco 2: Sociodemográficas } \\
\hline \multicolumn{4}{|l|}{ Sexo } \\
\hline Masculino & $1,52(1,03-2,24)$ & $1,40(0,94-2,08)$ & $1,22(0,81-1,83)$ \\
\hline \multicolumn{4}{|l|}{ Faixa etária (em anos) } \\
\hline 15 a 29 & $5,61(2,31-13,60)$ & $4,28(1,71-10,69)$ & $3,15(1,24-8,02)$ \\
\hline 30 a 44 & $3,91(1,64-9,30)$ & $3,18(1,31-7,72)$ & $2,42(0,98-5,95)$ \\
\hline 45 a 59 & $2,30(0,91-5,81)$ & $2,02(0,79-5,15)$ & $1,78(0,69-4,55)$ \\
\hline \multicolumn{4}{|l|}{ Cor da pele ${ }^{c}$} \\
\hline Parda ou preta & $1,49(0,99-2,23)$ & $1,49(0,99-2,24)$ & $1,56(1,03-2,35)$ \\
\hline \multicolumn{4}{|l|}{ Convivência marital } \\
\hline Não & $1,50(1,02-2,20)$ & $1,47(1,00-2,17)$ & $1,49(1,01-2,21)$ \\
\hline \multicolumn{4}{|c|}{ Bloco 3: Experiências no trânsito } \\
\hline \multicolumn{4}{|c|}{ Tipo de condutor } \\
\hline Motociclista & & $1,51(1,02-2,23)$ & $1,73(1,15-2,60)$ \\
\hline \multicolumn{4}{|l|}{ Antecedentes de multa } \\
\hline Sim & & $2,02(1,21-3,37)$ & $1,75(1,04-2,94)$ \\
\hline \multicolumn{4}{|l|}{ Bloco 4: Comportamentos } \\
\hline \multicolumn{4}{|l|}{ Beber e dirigir } \\
\hline Sim & & & $1,68(1,12-2,53)$ \\
\hline \multicolumn{4}{|c|}{ Uso de celular enquanto dirige } \\
\hline Sim & & & $1,63(1,09-2,43)$ \\
\hline \multicolumn{4}{|c|}{ 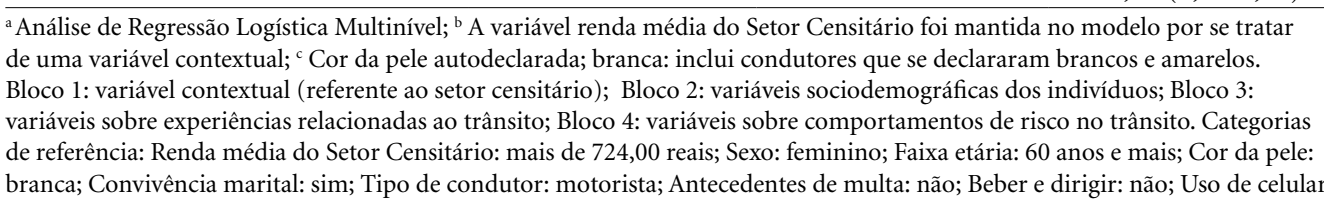 } \\
\hline
\end{tabular}

\section{Discussão}

Os fatores associados ao envolvimento em acidentes de trânsito entre condutores de veículos foram investigados por meio de abordagens pouco usuais no país, como o inquérito de base populacional e a aplicação de modelo hierarquizado.

Observou-se que o estudo, embora restrito à população de condutores, encontrou resultados que seguiram o padrão sociodemográfico de ocorrência da morbimortalidade por AT no país e no mundo, com maior proporção de acidentes para o sexo masculino e jovens, corroborando achados nacionais $^{14,25,27}$ e internacionais ${ }^{28,29}$, assim como entre aqueles de cor da pele preta ou $\operatorname{parda}^{11}$, solteiros ${ }^{30}$, que usam motocicleta ${ }^{11,12}$ e que referem antecedentes de multa e comportamentos inseguros no trânsito ${ }^{27,31,32}$.

Apesar da maior proporção de AT observada entre homens, o sexo deixou de estar associado ao envolvimento em acidentes a partir da inclusão das variáveis sobre experiência no trânsito. O valor da razão de chances tornou-se ainda mais reduzido quando da introdução das variáveis sobre comportamentos de risco. A ausência de associação entre sexo e envolvimento em AT no modelo final pode sugerir que o efeito desta exposição so- 
bre o desfecho seja mediado pelas variáveis que refletem experiências no trânsito e condutas arriscadas, o que é plausível, uma vez que estudos mostram diferenciais de gênero no engajamento em comportamentos de risco e em violações no trânsito ${ }^{33}$. A literatura sobre o tema aponta maior risco de AT para homens e, no presente estudo, observou-se maior frequência de acidentes nos condutores do sexo masculino, assim como foi notado que, no modelo multivariado final, a razão de chances para homens foi $22,0 \%$ maior do que para mulheres, embora esta diferença não tenha apresentado significância estatística. O que os dados do modelo final podem indicar é que, uma vez tendo adotado condutas de risco, homens e mulheres estariam igualmente expostos aos AT.

Há consenso na literatura científica, até o momento, que o maior envolvimento dos homens em acidentes se deve a diferenças de gênero, manifestadas pela maior exposição histórica do sexo masculino à motorização, assim como por representações de virilidade ao assumir condutas agressivas durante a condução de veículos ${ }^{28,29,33}$. Entretanto, com a intensa motorização contemporânea, observa-se a participação crescente das mulheres como condutoras de veículos e, mais recentemente, como condutoras de motocicletas. Tal fato pode contribuir para a redução das diferenças na frequência de AT entre os sexos, sinalizando, talvez, para uma redução do perfil "masculinizado" dos acidentes com condutores.

Ademais, algumas pesquisas internacionais não verificaram diferenças para certas condutas de risco no trânsito entre homens e mulheres, como o estudo de Wickens et al. ${ }^{34}$, realizado no Canadá, sobre direção agressiva, e o de Lonczak et al. ${ }^{35}$, que estudou aspectos de "angry driving" com condutores dos Estados Unidos. Necessário salientar que se tratam de achados em diferentes culturas, com níveis avançados de motorização e organização viária. Mesmo assim, trazem indícios de uma possível mudança, tanto nos padrões de exposição quanto no de condutas das mulheres no trânsito. No Brasil, pesquisadores apontam para o crescimento da representação das mulheres nos acidentes como condutoras ${ }^{36,37}$.

A análise hierarquizada mostrou que $\mathrm{o}$ envolvimento em AT esteve associado a fatores que encontram paralelo na literatura. Observou-se efeito tipo dose-resposta entre as categorias da faixa etária, com aumento na frequência de acidentes na medida em que diminuía a faixa de idade. Entretanto, pode-se verificar que esta variável exerceu efeito mediado sobre o desfecho, uma vez que a medida de associação foi reduzida nos Modelos B e C, mantendo maior proporção de envolvimento somente entre os condutores mais jovens, corroborando outros estudos ${ }^{12,14,25,29}$ e enfatizando a transcendência do fenômeno AT, ao apresentar grande potencial de perda produtiva e incapacitação precoce.

A cor da pele foi outro fator associado ao envolvimento em acidentes, tendo os condutores de cor preta ou parda maior proporção do evento. Esse resultado é consistente com o perfil encontrado, de modo geral, para as causas externas no país ${ }^{11,38,39}$, expressando as iniquidades sociais dos acidentes de trânsito. Uma das explicações para essa desigualdade seria a condição de maior vulnerabilidade a que as pessoas negras estão submetidas no ambiente viário, uma vez que, devido à exclusão social de grande parte desses indivíduos, acabam por constituir a maioria dos usuários vulneráveis da via pública ${ }^{40}$.

A respeito dos condutores de motocicleta, verificou-se maior frequência de acidentes neste grupo, o que reflete o padrão nacional contemporâneo para as ocorrências no trânsito, com predomínio dos usuários de motocicleta como vítimas de AT. Dados do Ministério da Saúde apontam que os ocupantes de moto correspondem à maioria das vítimas nos registros dos sistemas de informação do SUS, desde o atendimento ambulatorial, monitorado pelo VIVA ${ }^{11}$, até as estatísticas de óbito ${ }^{8}$. No cenário nacional, a Região Nordeste apresenta um quadro preocupante quanto às ocorrências envolvendo esta categoria $^{14}$. Estudos constatam o crescimento da violência no trânsito envolvendo motos nesta Região, especialmente em cidades de pequeno porte ${ }^{16} \mathrm{e}$ fora do eixo metropolitano ${ }^{41}$.

A gênese dos acidentes envolvendo motociclistas no Brasil é bastante complexa, pois envolve macrodeterminates com elementos políticos, econômicos e sociais, somados a fatores relacionados ao estilo de condução e maior vulnerabilidade no trânsito, inerente a esse tipo de veículo. Podem-se destacar como alguns macrodeterminantes: i) a opção política pelo transporte individual e incentivos fiscais dirigidos às montadoras de veículos; ii) a situação de desemprego para um grande contingente populacional, que viu no uso da motocicleta uma possibilidade de renda; iii) a ascensão de ocupações com o uso da moto, nas quais estão presentes as lógicas da celeridade e da remuneração por produtividade; e iv) facilidades de aquisição e menor custo de manutenção deste veículo $^{42,43}$.

Esse quadro contribuiu para que a motocicleta se avolumasse no trânsito, assumindo diferen- 
tes papeis na sociedade, suprindo demandas de deslocamento individual, algumas vezes familiar, em um contexto de precária mobilidade urbana e congestionamento das vias públicas, e funcionando como instrumento de trabalho. Acrescemse, ainda, o baixo investimento governamental em medidas de engenharia de tráfego apropriadas às motos, devido ao privilégio histórico dos automóveis no ambiente viário ${ }^{43,44}$.

O município de Jequié apresenta características que vão ao encontro dos determinantes, apontados pela literatura, para produção de acidentes com motociclistas. Uma delas é a grande frota de motocicletas da cidade, que, desde 2007, supera a frota de automóveis e demais veículos. Em 2006, as motos (motocicletas e motonetas) respondiam por $38,3 \%$ da frota local, alcançando $50,3 \%$ em 2013, enquanto a proporção de automóveis passou de $41,6 \%$ para $33,9 \%$ nesse mesmo período ${ }^{21}$. Tais dados mostram uma verdadeira "transição veicular" no local, com presença massiva de um veículo inerentemente vulnerável.

Outro fator que se mostrou associado ao envolvimento em AT foi ter sido multado no trânsito. O estudo de Marín-Leon e Vizzotto ${ }^{27}$, com condutores jovens, encontrou associação entre histórico de multa e envolvimento em acidentes somente para o grupo dos homens. Os autores consideraram o "histórico de ter sido multado no trânsito" como uma variável que carrega, nela mesma, transgressões de normas e, por isso, esta seria uma expressão de comportamentos inadequados no trânsito, que contribuem para o aumento do risco de acidentes. Concorda-se com essa hipótese, ainda mais porque, após a inclusão das variáveis do último Bloco (sobre comportamentos de risco), a medida de associação entre antecedentes de multa e envolvimento em AT foi reduzida, o que sugere um efeito mediado pelas variáveis comportamentais estudadas.

Quanto aos comportamentos de risco, apenas adotar velocidade insegura na via urbana não apresentou associação com o desfecho. Condutores que referiram dirigir após ingerir bebida alcoólica apresentaram chance de envolvimento em AT 68,0\% maior do que os que não referiram, o que mostra um resultado preocupante, mas, consistente com achados de pesquisas realizadas no país ${ }^{27}$ e até mesmo em outros contextos culturais, como Nova Zelândia ${ }^{45}$ e Franç̧ ${ }^{46}$.

A associação entre álcool e direção é um dos principais fatores de risco para ocorrência de acidentes de trânsito no mundo ${ }^{4} \mathrm{e}$, por isso, diversos países estabeleceram em suas legislações níveis máximos de tolerância de álcool no sangue. Ape- sar da existência do aparato legal de "tolerância zero" para alcoolemia no Brasil, estabelecida pela Lei $n^{\circ} 11.705 / 2008$ ("Lei Seca"), o comportamento de beber e dirigir ainda se faz presente no cotidiano da sociedade brasileira, uma vez que $24,3 \%$ dos adultos participantes da PNS afirmaram conduzir veículo após ingestão de qualquer quantidade de bebida alcoólica ${ }^{47}$. Com efeito, pela relevância que esse comportamento apresenta na geração de acidentes, ele foi selecionado como um dos alvos nacionais para as ações do Projeto Vida no Trânsito, implantado no Brasil entre 2010 e 2011, consonante à Década de Segurança no Trânsito ${ }^{6}$.

Outro fator de ordem comportamental que apresentou associação com o envolvimento em AT foi o uso de telefone celular. Enquanto no Brasil são raras as pesquisas que abordaram esse comportamento na ocorrência de acidentes ${ }^{48}$, em outros países há produção de evidências ${ }^{32,46}$ sobre o perigo do uso de telefone celular durante a condução de veículos, como a pesquisa longitudinal realizada na França, que encontrou risco relativo para AT com lesões de 1,88 (IC95\%: 1,35-2,61) entre os que sempre o usavam enquanto dirigiam ${ }^{46}$.

A OMS aponta que o risco de sofrer acidentes de trânsito entre quem usa celular na direção pode variar de duas a nove vezes o risco dos que não utilizam esse aparelho e, por isso, lançou em 2011 o documento Mobile phone use: a growing problem of driver distraction, com o qual espera aumentar a conscientização sobre os riscos desse comportamento. Além disso, incentiva a produção de conhecimento sobre o tema, que é relativamente recente e permanece desconhecido em muitas nações ${ }^{31}$.

O uso de aparelhos celulares durante a direção de veículos é uma conduta contemporânea, que compartilha de alguns determinantes já abordados para outros fatores associados, como a precariedade na fiscalização, sensação de impunidade e questões relativas aos processos de trabalho, como as ocupações que têm o veículo e o celular, juntos, como instrumentos para o trabalho. Além desses determinantes, há também outros fatores mais recentes, como o intenso uso deste aparelho pela sociedade nos últimos anos. A relação entre uso de celular e ocorrência de AT tem como processo subjacente o deslocamento da atenção das tarefas primárias (processos cognitivos da condução do veículo) para tarefas secundárias (uso do aparelho). Esse desvio, conhecido como distração cognitiva, é apontado como tão prejudicial ao desempenho do condutor quanto os efeitos do álcool ${ }^{31}$. 
Quanto às limitações da presente pesquisa, menciona-se o viés de sobrevivência e as dificuldades operacionais para alcançar o tamanho final da amostra, pois não foi possível encontrar alguns condutores em todas as tentativas estipuladas para realização da entrevista até o final do período de coleta. Mesmo assim, observaram-se importantes associações que foram coerentes e consistentes com os achados da literatura nacional e internacional sobre o tema. É possível que alguns resultados possam ter sido subestimados, tanto devido à questão amostral quanto devido à natureza de alguns assuntos, que são socialmente condenáveis e legalmente proibidos e, portanto, passíveis de serem omitidos pelos respondentes. No entanto, a magnitude observada para as frequências dos comportamentos de risco e das medidas de associação desses fatores com o envolvimento em AT expressam a gravidade da insegurança viária contemporânea.

Para concluir, observaram-se importantes fatores sociodemográficos e comportamentais associados ao envolvimento em acidentes de trânsito, com maior proporção desse evento no grupo de jovens, pardos ou pretos, sem convivência marital, motociclistas, com antecedentes de multa no trânsito e que adotam comportamentos de risco nesse ambiente, como beber e dirigir e uso do celular durante a condução de veículos. Um achado interessante, que difere da maior parte das evidências sobre o tema, foi a ausência de associação entre AT e sexo quando incluídas outras variáveis no modelo. Tal resultado pode ser explicado, em parte, pelo efeito de mediação de outros fatores de exposição posteriormente introduzidos, assim como por influência do poder da amostra. Por outro lado, também pode indicar redução das desigualdades de gênero nas ocorrências de trânsito. Observou-se que os fatores proximais modificaram as medidas de associação das exposições dos níveis superiores de determinação do modelo hierarquizado, o que sugere algum efeito mediado por esses fatores comportamentais, disparadores do evento.

Desse modo, os resultados deste estudo ratificam tanto o potencial de prevenção dos acidentes de trânsito, em virtude dos fatores evitáveis associados ao desfecho, quanto à urgência por investimentos em intervenções educativas e fiscalizadoras no trânsito e, sobretudo, em políticas de mobilidade segura que priorizem os deslocamentos de caráter coletivo.

\section{Colaboradores}

PAA Rios participou da concepção do projeto, da coleta, análise e interpretação dos dados, redação de todas as versões do artigo e aprovação da redação final. ELA Mota participou da concepção do projeto, da análise e interpretação dos dados, da revisão de todas as versões do artigo e da aprovação da redação final. LN Ferreira e JP Cardoso participaram da coleta, análise e interpretação dos dados, revisão crítica e aprovação da redação final. VM Ribeiro e BS Souza participaram da coleta, interpretação dos dados, revisão crítica e aprovação da redação final. Todos os autores contribuíram na revisão final do artigo. 


\section{Referências}

1. World Health Organization (WHO). Global status report on road safety: time for action. Genebra: WHO; 2009.

2. Instituto de Pesquisa Econômica Aplicada (IPEA), Agência Nacional de Transportes Públicos (ANTP). Impactos sociais e econômicos dos acidentes de trânsito nas aglomerações urbanas brasileiras: relatório executivo. Brasília: IPEA, ANTP; 2003.

3. Vasconcellos EA. Políticas de Transporte no Brasil: a construção da mobilidade excludente. Barueri: Manole; 2013.

4. World Health Organization (WHO). Global status report on road safety 2013: supporting a decade of action. Genebra: WHO; 2013.

5. World Health Organization (WHO). Global plan for the Decade of Action for Road Safety 2011-2020 [página na Internet]. 2010 [acessado 2017 Jul 16]. Disponível em: http://www.who.int/roadsafety/decade_of_ action/plan/en/

6. Morais Neto OL, Silva MMA, Lima CM, Malta DC, Silva Júnior JB. Projeto Vida no Trânsito: avaliação das ações em cinco capitais brasileiras, 2011-2012. Epidemiol Serv Saude 2013; 22(3):373-382.

7. Blumenberg C, Martins RC, Costa JC, Ricardo LIC. Is Brazil going to achieve the road traffic deaths target? An analysis about the sustainable development goals. Inj Prev 2018; 24(4):250-255.

8. Brasil. Ministério da Saúde (MS). DATASUS/Sistema de Informações sobre Mortalidade [página na Internet]. 2017 [acessado 2017 Mar 3]. Disponível em: http://www2.datasus.gov.br/DATASUS/index.php?area $=0205$

9. Brasil. Ministério da Saúde (MS). DATASUS/Sistema de Informação Hospitalar [página na Internet]. 2017 [acessado 2017 Mar 20]. Disponível em: http://www2. datasus.gov.br/DATASUS/index.php?area=0203

10. Bahia CA, Malta DC, Mascarenhas MDM, Montenegro MMS, Silva MMA, Monteiro RA. Acidentes de transporte terrestre no Brasil: mortalidade, internação hospitalar e fatores de risco no período 20022012. In: Brasil. Ministério da Saúde (MS). Departamento de Análise de Situação em Saúde. Saúde Brasil 2012: uma análise da situação de saúde e dos 40 anos do Programa Nacional de Imunizações. Brasília: MS; 2013. p. 299-326.

11. Brasil. Ministério da Saúde (MS). DATASUS/Sistema de Vigilância de Violências e Acidentes [página na Internet]. 2015 [acessado 2015 Set 25]. Disponível em: http://tabnet.datasus.gov.br/cgi/deftohtm.exe?viva/2011/vival1p.def

12. Malta DC, Mascarenhas MDM, Bernal RTI, Silva MMA, Pereira CA, Minayo MCS, Morais Neto OL. Análise das ocorrências das lesões no trânsito e fatores relacionados segundo resultados da Pesquisa Nacional por Amostra de Domicílios (PNAD) - Brasil, 2008. Cien Saude Colet 2011; 16(9):3679-3687.
13. Malta DC, Andrade SSCA, Gomes N, Silva MMA, Morais Neto OL, Reis AAC, Nardi ACF. Lesões no trânsito e uso de equipamento de proteção na população brasileira, segundo estudo de base populacional. Cien Saude Colet 2016; 21(2):399-409.

14. Morais Neto OL, Andrade AL, Guimarães RA, Mandacarú PMP, Tobias GC. Regional disparities in road traffic injuries and their determinants in Brazil, 2013. Int J Equity Health 2016; 15:142.

15. Waiselfisz JJ. Mapa da violência dos municípios brasileiros. Brasília: RITLA/Instituto Sangari/MS/MJ; 2008.

16. Morais Neto OL, Montenegro MMS, Monteiro RA, Siqueira Júnior JB, Silva MMA, Lima CM, Miranda LOM, Malta DC, Silva Júnior JB. Mortalidade por Acidentes de Transporte Terrestre no Brasil na última década: tendência e aglomerados de risco. Cien Saude Colet 2012; 17(9):2223-2236.

17. Caiffa WT, Friche AAL. Urbanização, globalização e segurança viária: um diálogo possível em busca da equidade? Cien Saude Colet 2012; 17(9):2237-2245.

18. Hoffmann MH. Comportamento do condutor e fenômenos psicológicos. Psicologia: Pesquisa Trânsito 2005; 1:17-24.

19. Bahia. Superintendência de Estudos Econômicos e Sociais da Bahia. Regióes Econômicas do Estado da Bahia [mapa na Internet]. 2015 [acessado 2015 Nov 20]. Disponível em: http://www.sei.ba.gov.br/site/geoambientais/mapas/pdf/regioes_economicas_2015.pdf

20. Brasil. Instituto Brasileiro de Geografia e Estatística (IBGE). Estimativas populacionais [página na Internet]. 2013 [acessado 2014 Jul 29]. Disponível em: http://www.ibge.gov.br/home/estatistica/populacao/ estimativa2013/ estimativa_dou.shtm

21. Brasil. Departamento Nacional de Trânsito (Denatran). Frota de veículos [página na Internet]. 2013 [acessado 2014 Jun 1]. Disponível em: http://www. denatran.gov.br/frota.htm

22. Magalhães AF, Lopes CM, Koifman RJ, Muniz PT. Caracterização dos acidentes de trânsito auto-referidos, em inquérito de base populacional, Rio Branco, Acre, 2008. In: Magalhães AF. Prevalência dos acidentes de trânsito auto-referidos em Rio Branco-Acre [dissertação]. Rio Branco: Universidade Federal do Acre; 2009. p. 54-79.

23. Brasil. Instituto Brasileiro de Geografia e Estatística (IBGE). Censo 2010 [página na Internet]. 2010 [acessado 2013 Jan 9]. Disponível em: http://www.censo2010.ibge.gov.br/

24. Organização Mundial da Saúde (OMS). Classificação Estatística Internacional de Doenças e Problemas relacionados à Saúde - $10^{a}$ revisão [página na Internet]. 2008 [acessado 2013 Out 6]. Disponível em: http:// www.datasus.gov.br/cid10/V2008/cid10.htm

25. Magalhães AF, Lopes CM, Koifman RJ, Muniz PT. Prevalência de acidentes de trânsito auto-referidos em Rio Branco, Acre. Rev Saude Publica 2011; 45(4):73844. 
26. Fuchs SC, Victora CG, Fachel J. Modelo hierarquizado: uma proposta de modelagem aplicada à investigação de fatores de risco para diarreia grave. Rev Saude Publica 1996; 30(2):168-78.

27. Marín-Leon L, Vizzotto MM. Comportamentos no trânsito: um estudo epidemiológico com estudantes universitários. Cad Saude Publica 2003; 19(2):515523.

28. Özkan T, Lajunen T. What causes the differences in driving between young men and women? The effects of gender roles and sex on young drivers' driving behavior and self-assessment of skills. Transportation Research Part F 2006; 9(4):269-277.

29. Factor R, Mahalel D, Yair G. Inter-group differences in road-traffic crash involvement. Accid Anal Prev 2008; 40(6):2000-2007.

30. Whitlock G, Norton R, Clark T, Jackson R, MacMahon S. Motor vehicle driver injury and marital status: a cohort study with prospective and retrospective driver injuries. J Epidemiol Community Health 2003; 57:512-516.

31. World Health Organization (WHO). Mobile phone use: a growing problem of driver distraction. Genebra: WHO; 2011.

32. Korpinen L, Pääkkönen R. Accidents and close call situations connected to the use of mobile phones. Accid Anal Prev 2012; 45:75-82.

33. McDonald CC, Sommers MS, Fargo JD. Risky driving, mental health, and health-compromising behaviours: risk clustering in late adolescents and adults. Inj Prev 2014; 20:365-372.

34. Wickens CM, Manna RE, Stoduto G, Butters JE, Ialomiteanu A, Smart RG. Does gender moderate the relationship between driver aggression and its risk factors? Accid Anal Prev 2012; 45:10-18.

35. Lonczak HS, Neighbors C, Donovan DM. Predicting risky and angry driving as a function of gender. Accid Anal Prev 2007; 39(3):536-545.

36. Davantel PP, Pelloso SM, Carvalho MDB, Oliveira NLB. A mulher e o acidente de trânsito: caracterização do evento em Maringá, Paraná. Rev Bras Epidemiol 2009; 12(3):355-367.

37. Bringmann PB, Ferreira EC, Bringmann NV, Pelloso SM, Carvalho MDB. Um padrão de envolvimento dos adultos em acidentes rodoviários. Cien Saude Colet 2014; 19(12):4861-4868.

38. Neves ACM, Mascarenhas MDM, Silva MMA, Malta DC. Perfil das vítimas de violências e acidentes atendidas em serviços de urgência e emergência do Sistema Único de Saúde em capitais brasileiras - 2011. Epidemiol Serv Saude 2013; 22(4):587-559.

39. Araújo EM, Costa MCN, Hogan VK, Mota ELA, Araújo TM, Oliveira NF. Diferenciais de raça/cor da pele em anos potenciais de vida perdidos por causas externas. Rev Saude Publica 2009; 43(3):405-412.

40. Brasil. Ministério da Saúde (MS). Conselho Nacional de Secretários de Saúde (CONASS). Violência: uma epidemia silenciosa. Brasília: CONASS; 2007.
41. Silva PHNV, Lima MLC, Moreira RS, Souza WV, Cabral APS. Estudo espacial da mortalidade por acidentes de motocicleta em Pernambuco. Rev Saude Publica 2011; 45(2):409-415.

42. Brasil. Ministério da Saúde (MS). Departamento de Análise de Situação de Saúde. Impacto da violência na saúde dos brasileiros. Brasília: MS; 2005.

43. Vasconcellos EA. O custo social da motocicleta no Brasil. Rev Transp Publicos 2008; 30/31:127-142.

44. Marín-Leon L, Belon AP, Barros MBA, Almeida SDM, Restitutti MC. Tendência dos acidentes de trânsito em Campinas, São Paulo, Brasil: importância crescente dos motociclistas. Cad Saude Publica 2012; 28(1):3951.

45. Horwood LJ, Fergusson DM. Drink driving and traffic accidents and Young people. Accid Anal Prev 2000; 32(6):805-814.

46. Constant A, Salmi LR, Lafont S, Chiron M, Lagarde E. Road casualties and changes in risky driving behavior in france between 2001 and 2004 among participants in the GAZEL Cohort. Am J Public Health 2009; 99(7):1247-1253.

47. Brasil. Instituto Brasileiro de Geografia e Estatística (IBGE). Pesquisa Nacional de Saúde 2013: percepção do estado de saúde, estilos de vida e doenças crônicas. Rio de Janeiro: IBGE; 2014.

48. Souto CC, Reis FKW, Bertolini RPT, Lins RSMA, Souza SLB. Perfil das vítimas de acidentes de transporte terrestre relacionados ao trabalho em unidades de saúde sentinelas de Pernambuco, 2012 - 2014 Epidemiol Serv Saude 2016; 25(2):351-361.

Artigo apresentado em 22/12/2017

Aprovado em 18/06/2018

Versão final apresentada em 20/06/2018 
